\title{
Anticipated reinforcement and attraction
}

\author{
WILLIAM B. GRIFFITT, DEPARTMENT OF PSYCHOLOGY, \\ UNIVERSITY OF HAWAII, Honolulu, Hawaii 96822
}

Implicit affective responses, hypothesized to be, in part, anticipations of future reinforcement, are proposed to mediate the relationship between reinforcement and attraction. In the present experiment, it was found that attraction responses are more positive to an individual from whom Ss anticipate positive reinforcement than to one from whom negative reinforcement is anticipated $(p<.01)$. In addition, attraction was found to be a positive function of the proportion of similar attitudes expressed by a stranger $(p<.001)$. The results were in clear support of a reinforcement model of attraction.

Growing out of a large body of research (Byme, in press; Lott \& Lott, in press) has emerged the makings of a formal model which places the determinants of attraction among individuals in the framework of S-R learning and reinforcement theory. Within this context, attraction responses are conceptualized as one type of a more general class of evaluative responses. It is proposed (Byrne \& Clore, 1967; Griffitt, in press) that the evaluation of a given stimulus object (SO) is a positive linear function of the proportion of stimuli with weighted positive reinforcement properties associated with SO. Stimuli with reinforcement properties (RS) are hypothesized to evoke implicit affective responses (AR) which become conditioned to any SO paired with RS and subsequently mediate verbal evaluative responses to $S O$.

A good deal of evidence has accumulated in support of the latter propositions. For example, it has been shown (Byrne, Young, \& Griffitt, 1966) that agreeing and disagreeing attitude statements act, respectively, as positive and negative reinforcements. In addition, it is consistently found that attraction toward an anonymous stranger is a positive linear function of the proportion of agreeing attitudes expressed by the stranger (Byrne, in press). Further, Byrne \& Clore (1967) have demonstrated that positive or negative affect may be conditioned to anonymous strangers by pairing the latter with agreeing or disagreeing attitude statements.

Reinforcing stimuli are assumed to evoke affective responses which represent, at least in part, reactions which are "expectative" (Hull, 1952), "hopeful" (Mowrer, 1960), or "anticipatory" (Doob, 1947) of future reinforcement. Thus, if a positive or negative anticipatory $A R$ is associated with a particular SO, evaluative or attraction responses to that SO should be either positive or negative. The present study was designed to assess the effects of a direct manipulation of anticipation of positive or negative reinforcement on attraction and compare such effects with those of a manipulation of RS hypothesized to affect AR and subsequent evaluative responses in a similar fashion. Specifically, it was hypothesized that Ss are more attracted to a stranger from whom they anticipate positive reinforcement than to one from whom they anticipate negative reinforcement and that attraction is a positive function of the proportion of similar attitudes expressed by a stranger.

Method. Students in an introductory psychology course were administered a 12-item attitude scale. From this initial pool, 40 male and female $S s$ were selected for the experiment. Several weeks after the initial testing, Ss were requested to evaluate an anonymous same-sex stranger on the basis of inspection of his responses to the attitude scale. All Ss were told that the attitude scale which they were to inspect had been filled out by another student who, in a second part of the experiment, was going to act as their $E$
Table 1

Mean Attraction Responses as a Function of Attitude Similarity and Anticipated Reinforcement

\begin{tabular}{lccr} 
& .25 & .75 & Total \\
\hline Positive & 9.40 & 11.60 & 10.50 \\
Negative & 7.70 & 10.30 & 9.00 \\
Total & 8.55 & 10.95 & \\
\hline
\end{tabular}

in a discrimination leaming experiment. Half of the Ss were told that their $\mathrm{E}$ would positively reinforce each correct response with $5 \mathrm{c}$ and ignore incorrect responses (anticipation of positive reinforcement) while the other half were told that their $\mathrm{E}$ would negatively reinforce each incorrect response with a painful shock and ignore correct responses (anticipation of negative reinforcement). In addition, the attitude scale responses attributed to the stranger were bogus ones prepared to provide .25 agreement with $\mathrm{Ss}$ in half of each "anticipation" condition and .75 agreement in the other half of each anticipation condition. The mythical "Es" were evaluated on the Interpersonal Judgment Scale, the last two items of which are summed to yield the measure of attraction.

Results. The means of the attraction responses are shown in Table 1. Analysis of variance indicated that both the agreementdisagreement variable $(F=19.01, \mathrm{df}=1 / 36, \mathrm{p}<.001)$ and the anticipation variable $(F=7.43, \mathrm{df}=1 / 36, \mathrm{p}<.01)$ yielded highly significant effects. The interaction $F$ ratio was less than one.

Discussion. Although the nature of the hypothetical AR has obviously not been identified, it appears that a direct manipulation of anticipation of positive or negative reinforcement associated with a stranger does affect attraction toward the stranger in the expected manner. In addition, the familiar relationship between attitude similarity and attraction has once again been demonstrated. The issue remains, however, concerning whether RS evoke an AR which is anticipatory of future positive or negative reinforcement. An investigation designed to further examine this issue is now underway. Briefly, a situation has been created in which Ss receive positive or negative RS from an individual with whom they expect to interact. In addition to evaluating the individual, Ss are asked to predict the nature of the pending interaction in terms of positive or negative reinforcement. It is expected that predictions of future reinforcement, as well as attraction, will be affected by RS.

\section{REFERENCES}

BYRNE, D. Attitudes and attraction. In L. Berkowitz (Ed.), Advences in experimental social psychology. Vol. 4. New York: Academic Press, in press.

BYRNE, D., \& CLORE, G. L., Jr. A reinforcement model of evaluative responses. Unpublished, 1967.

BYRNE, D., YOUNG, R. K., \& GRIFFITT, w. The reinforcement properties of attitude statements. J. exp. res. Pers, 1966, 1, 266-276.

DOOB, L. W. The behavior of attitudes. Psychol Rev., 1947, 54, $135-156$.

GRIFFITT, W. B. Attraction toward a stranger as a function of direct and associated reinforcement. Psychon. Sci, in press.

HULL, C. L. A behavior system. New Haven: Yale University Press, 1952.

LOTT, A. J., \& LOTT, B. E. A learning theory approach to interpersonal attitudes. In T. C. Brock, A. G. Greenwald, \& T. M. Ostrom (Eds.), Attitude change theory and research. New York: Academic Press, in press. MOWRER, O. H. Learning theory and behavior. New York: Wiley, 1960.

\section{NOTE}

1. This research was supported in part by a grant from the University Research Council of the University of Hawaii. Portions of this research were presented at the meetings of the Southwestern Psychological Association, April, 1968, New Orleans, Louisiana. 